\title{
Contraception Choice among HIV-Positive Women Utilizing Family Planning Services Integrated with HIV Care at the Antiretroviral Therapy Clinic of Jos University Teaching Hospital, Nigeria
}

\author{
Halima Sule, Mark Gyang, Tinuade Oyebode and Margaret Tersoo
}

\section{ABSTRACT}

Transmission of Human Immunodeficiency Virus from a pregnant HIVinfected woman to her unborn child is one of the ways through which new HIV infections can be acquired. Utilization of contraceptives among HIVpositive women can prevent unintended pregnancies, and the use of dual methods reduces the risk of transmission of sexually transmitted infections including HIV, hence the need to support contraception in them. This study sought to describe the various choices of contraception used by women accessing family planning services integrated with the antiretroviral therapy facility of Jos University Teaching Hospital. In a retrospective study, relevant information was extracted from the records of all women who had sought contraception in the Family Planning unit of the facility from 1st March 2019 - 29th February 2020. The data obtained was analysed using EPI info 7 statistical software. Results: A total of 137 records were reviewed. The most frequent choice of contraception was hormonal implants $(61.3 \%)$, while the least frequent choice was using condoms alone $(1.5 \%)$. Less than half $(46.7 \%)$ of them used dual contraception. Secondary and tertiary educational status, as well as disclosure of HIV-positive status to partner were significantly associated with utilization of dual contraceptive methods $(P$ value $=0.0010$ and 0.0245 respectively; Odds ratio $=\mathbf{5 . 8 1 9 9}$ and 4.3307 respectively). Conclusion: Integration of family planning services with HIV care as a strategy for the prevention of unintended pregnancy is promoted in this facility but there is need to improve the uptake particularly of dual method of contraception. There is also need for inclusion of IUCD in the choices of contraception offered as this method is highly effective, long lasting and has been proven to be safe in well selected HIV patients. Furthermore, screening the clients to identify unmet needs and implementing strategies to meet those needs would enhance the impact of family planning.

Keywords: Contraception, Dual method, Family planning, HIVpositive women, Nigeria.

\section{INTRODUCTION}

It is estimated that 37.9 million people worldwide are currently infected with HIV, of which 36.2 million are adults (52\% women) and 1.7 million are children aged 15 years and below [1], [2]. Approximately $90 \%$ of infants infected with HIV acquire the virus from their HIV-infected mothers during pregnancy, delivery or breast-feeding [1]. Nigeria contributes about $26.9 \%$ of the total cases of perinatal transmission of HIV [3]. Sub-Saharan Africa has been identified as the region of the world most severely hit by the HIV scourge accounting for more than two-thirds of the global HIV infections, with women having the highest prevalence of the disease. Statistics have shown that Nigeria
Published Online: October 5, 2020

ISSN: 2593-8339

DOI: $10.24018 /$ ejmed.2020.2.5.475

H. Sule*

Department of Family Medicine University of Jos/Jos University Teaching Hospital, Nigeria.

(e-mail: haltsav@yahoo.com)

M. Gyang

Department of Family Medicine

University of Jos/Jos University

Teaching Hospital, Nigeria.

(e-mail: mdrgyang@gmail.com)

T. Oyebode

Department Obstetrics and

Gynaecology
University of Jos/Jos University

University of Jos/Jos
Teaching Hospital, Nigeria.

(e-mail: tinuadeoyebode@yahoo.com)

M. Tersoo

APIN Centre

Jos University Teaching Hospital,

Nigeria

(e-mail: mtersoo@ymail.com)

*Corresponding Author has the second largest HIV epidemic globally, and ranks top in having the highest rates of new infection in sub-Saharan Africa [4]. In Nigeria, the population of people living with HIV and AIDS (PLWHA) in 2018 was 1.9 million [5]. An estimated $58 \%$ of the people infected with HIV in Nigeria are women, and this higher prevalence in women has been linked to gender inequality in societal and cultural issues [6]. Most of these women are in the reproductive age group a potential which places them at risk for perinatal transmission of HIV; a significant contributor to new HIV infections [1]. Furthermore, HIV-positive pregnant women in sub-Saharan Africa have been reported to have about 8 times higher mortality than HIV-negative women [7].

The era of antiretroviral therapy (ART) has made it 
possible for more women infected with HIV to live longer healthier lives. With improved health status, comes an accompanying renewed interest and ultimately resumption in sexual activities that could result in pregnancy, most of which are unplanned pregnancies including repeat unplanned pregnancies as have been reported by some studies [8]-[10]. Unplanned pregnancies occur more commonly among HIV-infected women than non HIVinfected women [11]. Such unplanned pregnancies are associated with consequences in the mother and baby; one of which is high viral load in the mother that predisposes to increased risk of $15 \%-45 \%$ for mother to child transmission of HIV, in the absence of any intervention [12]. This is responsible for over $90 \%$ of paediatric HIV infections. Also associated with unplanned pregnancy in HIV-positive women is an increased risk for miscarriage, still birth and other adverse outcomes of pregnancy. Unplanned pregnancies in HIV-positive women may lead to procurement of induced abortion with its attendant risks [8], [13].

Preventing unintended pregnancies in HIV-positive women can be achieved through the use of family planning (FP). Escalating the use of FP among HIV-positive women has been reported to prevent $29 \%$ more HIV-positive births than the use of prophylactic nevirapine alone in newborns [14]. The role of FP in preventing unplanned pregnancy, is well-recognized in the prevention of transmission of HIV from an infected mother to her child, and is one of the core elements of Prevention of Mother to Child Transmission (PMTCT) conceptualized by the World Health Organization (WHO). This strategy decreases the risk of perinatal HIV infection and allows a woman infected with HIV plan her family size and space her children thereby reducing pregnancy related complications and maintaining good reproductive health [15].

Modern reversible contraceptive methods exist that can be effectively used in HIV infected and uninfected women alike to prevent unintended pregnancies, however, unintended pregnancies have been reported to occur more in HIV- positive women [11] suggesting that HIV-positive women may not be using contraception as effectively as HIV-negative women. Various factors influence the use of contraception in HIV-positive women in Africa as have been reported by researchers in different parts of the continent [16]-[22]. The factors include age, marital status, educational level, current sexual activity, HIV disclosure status, counselling for contraception, private facility followup, ART status, discussing contraception with partner, partner consent and serodiscordancy. Most recorded low contraceptive use and high unmet need for contraception. The modern reversible contraceptive methods are categorized as short acting when used in short time intervals (e.g. single use [condom], daily intake [pills], up to 3 monthly applications injectables) and long acting such as the intrauterine contraceptive devices (IUCD) and contraceptive implants [23]. The long-acting reversible contraceptives (LARC) are the most effective reversible contraceptive methods. The variety of contraceptives may each be used exclusively as a single method (SM) or as a dual method (DM) where a non-barrier contraceptive is used in combination with condoms. DM contraception recommended for use in PLWHA has the advantage of lowering the risk of sexually transmitted infections including resistant strains of HIV between sexual partners and simultaneously better prevents unplanned pregnancy with its attendant risks to mother and child [24]. Though dual contraception is recommended for HIV-infected women some studies in developing countries have shown that the prevalence is low, and authors have reported that linking FP with ART services may promote the uptake of dual methods [8], [24], [26]. Integrating family planning services with HIV services is a strategy for increasing access to and use of contraception among women with HIV who do not wish to become pregnant. This will aid elimination of paediatric infections in addition to improving the reproductive health of the women. Since family planning services were integrated into the HIV care service of the ART clinic in JUTH, no study has been carried out to assess the pattern of contraception choice among the women enrolled in HIV care seeking birth control. The aim of this study was to assess the choices and factors associated with SM or DM of contraception used by HIV-infected women accessing HIV care at the AIDS Prevention Initiative Nigeria (APIN) Clinic of Jos University Teaching Hospital (JUTH), Jos, Nigeria. The results could form the background for improved effective FP services and further related studies.

\section{Materials And MethodS}

\section{A. Study design \& Patients}

The study was a retrospective hospital based study using data of all HIV-positive women of child bearing age, who attended the Family planning unit of the APIN centre from 1st March 2019 - 29th February 2020.

\section{B. Study Area}

The study area was the APIN centre, of JUTH, located in the urban city of Jos the capital of Plateau state, Nigeria. The centre provides comprehensive HIV care services including ART to adults, children and pregnant women in Adult, Paediatric and PMTCT clinics respectively, from Mondays to Fridays. Patients present from within Jos and environs for care, and the centre has served over 20,000 patients cumulatively. The total number of women of child bearing age enrolled for HIV care in the facility during the period of study was 4291(APIN data records). The FP unit was integrated into the HIV care services to improve access to birth control for HIV-infected women, particularly in those who desire contraception but may decline to seek contraception from other available sources outside the facility. Contraceptives methods provided included condoms, pills, injectables and implants, with a skilled FP nurse in attendance. Group counselling for family planning was provided in the adult clinic and PMTCT (postnatal) clinic as part of the routine health talk, while one on one/couple counselling was offered in the Family Planning unit. Patients who desired surgical methods of contraception or methods not provided in the unit were referred to the main Family Planning clinic of JUTH. No records were kept of such referrals. 


\section{Data Collection}

Sociodemographic and HIV-related information including the regular use of condoms was obtained from electronic data records for routine HIV patient care, while other information about reproductive history and choice of contraception was obtained from Family Planning records. Utilization of SM and DM were defined as the exclusive use of one of the available methods of contraception and the simultaneous use of one of the available non-barrier methods along with condoms respectively. No records were available for clients who were referred elsewhere. Out of a total of 143 client records, 6 were excluded from the study due to incomplete data leaving a total of 137 records for the final analysis.

\section{Ethical Consideration}

Ethical approval to carry out the study was obtained from JUTH Research and Ethics Committee, and approval was sought from the APIN Institutional Review Board.

\section{E. Data Analysis}

Data was analyzed using Epi info statistical software package version 7 (CDC Atlanta, GA). Categorical and continuous variables were presented as frequencies and percentages in tables and figures. Continuous variables were also presented as means and standard deviation. Choice of contraception was dichotomized into single and dual methods, and multiple logistic regression analysis was used to determine factors associated with method of contraception. A confidence interval of $95 \%$ was used and a $P$ value of $\leq 0.05$ was considered statistically significant.

\section{RESULTS}

One hundred and thirty-seven clients' records were analyzed. The mean age was $36.2 \pm 5.1$ years, with the greatest fraction of them aged 30-39 years $(61.3 \%)$, married (52.6\%), urban dwellers $(83.9 \%)$, and of the Christian faith (76.6\%). Seventy-three percent of them had attained secondary or tertiary education. The most frequent occupation encountered was being a housewife $(21.2 \%)$, followed by government workers (19.7\%). A greater proportion of them $(73.0 \%)$ had parity equal to or greater than 4 and those who had 3 or more children alive were $73.0 \%$ (Table I). The mean know duration of HIV infection was $12.9 \pm 3.0$ years, and the mean number of years on ART was $12.3 \pm 3.2$ years. More of the clients $(45 \%)$ belonged to WHO clinical class I. Sixty-nine percent of them had disclosed their HIV-positive status to their partners, and more than half of them $(58.4 \%)$ had partners that were also HIV positive while only $11.7 \%$ had partners that were HIV negative and the remaining $29.9 \%$ did not know their partners' HIV status. Eighty percent of the clients had a viral load of less than 1000 copies per ml (Table II). All the clients $(100 \%)$ received counselling prior to commencing any of the various methods however none of them was counselled with their partner. Overall, the most common method of contraception was the contraceptive implant $(61.3 \%)$, followed by condoms $(48.2 \%)$, injectables $(32.9 \%)$ and pills $4.4 \%$ (Table II). Implants, injectables, pills and condoms were used exclusively in $32 \%, 16 \%, 3 \%$ and $1.5 \%$ of the clients respectively, while $27.7 \%, 17.5 \%$ and $1.5 \%$ used implants, injectables and pills respectively in combination with condoms (Fig. 1). In total, $46.7 \%$ of the clients used dual contraception (Fig. 2). Utilization of DM was significantly associated with having a secondary/tertiary level of education and disclosure of HIV-positive status to partner $(\mathrm{P}$ value $=0.0010,0.0245$ and respectively). Clients with secondary/tertiary education were 6 times more likely to use DM (odds ratio $=5.8199$ ) while those who had disclosed their HIV positive status to their partners were 4 times more likely to use DM (odds ratio 4.3307). Age, marital status, religion, residence, known duration of HIV infection, number of children alive, parity, partner's HIV status and viral load level did not show any significant association with utilization of dual method of contraception.

\section{A. Figures and Tables}

TABLE I: SOCIODEMOGRAPHIC CHARACTERISTICS (N=137)

\begin{tabular}{|c|c|c|}
\hline Variables & Frequency & Percentage $\%$ \\
\hline \multicolumn{3}{|l|}{ Age group (years) } \\
\hline $18-29$ & 14 & 10.2 \\
\hline $30-39$ & 84 & 61.3 \\
\hline$\geq 40$ & 39 & 28.5 \\
\hline \multicolumn{3}{|l|}{ Marital status } \\
\hline Never married & 31 & 22.6 \\
\hline Married & 72 & 52.6 \\
\hline Separated & 8 & 5.8 \\
\hline Divorced & 7 & 5.1 \\
\hline Widowed & 19 & 13.9 \\
\hline \multicolumn{3}{|l|}{ Educational status } \\
\hline No formal education/primary & 37 & 27.0 \\
\hline Secondary/Tertiary & 100 & 73.0 \\
\hline \multicolumn{3}{|l|}{ Religion } \\
\hline Christianity & 105 & 76.6 \\
\hline Islam & 32 & 23.4 \\
\hline \multicolumn{3}{|l|}{ Domicile } \\
\hline Urban & 115 & 83.9 \\
\hline Rural & 22 & 16.1 \\
\hline \multicolumn{3}{|l|}{ Occupation } \\
\hline Student & 8 & 5.8 \\
\hline Housewife & 29 & 21.2 \\
\hline Government worker & 27 & 19.7 \\
\hline Trading & 21 & 15.3 \\
\hline Farming & 2 & 1.5 \\
\hline Artisan & 16 & 11.7 \\
\hline Private employee & 9 & 6.6 \\
\hline $\begin{array}{l}\text { Others (unemployed, applicants, } \\
\text { apprentices) }\end{array}$ & 25 & 18.2 \\
\hline \multicolumn{3}{|l|}{ Number of children alive } \\
\hline$\leq 2$ & 37 & 27.0 \\
\hline$\geq 3$ & 100 & 73.0 \\
\hline \multicolumn{3}{|l|}{ Parity } \\
\hline$\leq 3$ & 37 & 27.0 \\
\hline$\geq 4$ & 100 & 73.0 \\
\hline \multicolumn{3}{|l|}{$\begin{array}{l}\text { Received counselling for family } \\
\text { planning }\end{array}$} \\
\hline Yes & 137 & 100 \\
\hline No & - & - \\
\hline \multicolumn{3}{|l|}{$\begin{array}{l}\text { Received counselling with } \\
\text { partner }\end{array}$} \\
\hline Yes & - & - \\
\hline no & 137 & 100 \\
\hline
\end{tabular}


TABLE II: HIV RELATED CHARACTERISTICS/CONTRACEPTIVE CHOICE

\begin{tabular}{|c|c|c|}
\hline Variable & Frequency & Percentage $\%$ \\
\hline \multicolumn{3}{|l|}{ WHO class } \\
\hline I & 62 & 45.2 \\
\hline II & 40 & 29.2 \\
\hline III & 30 & 21.9 \\
\hline IV & 5 & 3.7 \\
\hline \multicolumn{3}{|c|}{ Duration of HIV diagnosis (years) } \\
\hline$\leq 10$ & 22 & 16.1 \\
\hline$>10$ & 115 & 83.9 \\
\hline \multicolumn{3}{|c|}{ Duration on ART (years) } \\
\hline$\leq 10$ & 22 & 16.1 \\
\hline$>10$ & 115 & 83.9 \\
\hline \multicolumn{3}{|c|}{ Disclosed status to partner } \\
\hline Yes & 95 & 69.3 \\
\hline No & 42 & 30.7 \\
\hline \multicolumn{3}{|c|}{ Partner's status } \\
\hline Positive & 80 & 58.4 \\
\hline Negative & 16 & 11.7 \\
\hline Unknown & 41 & 29.9 \\
\hline \multicolumn{3}{|c|}{ Most recent viral load copies $/ \mathrm{ml}$} \\
\hline$<1000$ & 110 & 80.3 \\
\hline$\geq 1000$ & 27 & 19.7 \\
\hline \multicolumn{3}{|c|}{$\begin{array}{l}\text { Received counselling for family } \\
\text { planning }\end{array}$} \\
\hline Yes & 137 & 100 \\
\hline \multicolumn{3}{|c|}{ Received counselling with partner } \\
\hline & 137 & 100 \\
\hline \multicolumn{3}{|c|}{$\begin{array}{l}\text { Absolute frequency of contraceptive } \\
\text { methods used }^{a}\end{array}$} \\
\hline Condoms & 66 & 48.2 \\
\hline Implants & 84 & 61.3 \\
\hline Injectables & 45 & 32.9 \\
\hline Pills & 6 & 4.4 \\
\hline
\end{tabular}

a Some clients used more than one method.

TABLE III: FACTORS ASSOCIATED WITH DUAL CONTRACEPTION USAGE

\begin{tabular}{|c|c|c|c|}
\hline Factors & $\begin{array}{l}\text { Odds } \\
\text { ratio }\end{array}$ & $\begin{array}{c}95 \% \text { confidence } \\
\text { interval }\end{array}$ & P-value \\
\hline \multicolumn{4}{|l|}{ Age group (years) } \\
\hline $18-29$ & 1 & - & - \\
\hline $30-39$ & 0.9923 & $0.2545-3.8693$ & 0.9911 \\
\hline$\geq 40$ & 0.7556 & $0.1676-3.4057$ & 0.7153 \\
\hline \multicolumn{4}{|l|}{$\bar{M}$ arital status } \\
\hline Never married & 1 & - & - \\
\hline Married & 0.4063 & $0.1143-1.4447$ & 0.1641 \\
\hline Separated & 0.4789 & $0.0842-2.7239$ & 0.4065 \\
\hline Divorced & 1.8838 & $0.2612-13.5870$ & 0.5299 \\
\hline Widowed & 0.7282 & $0.1799-2.9472$ & 0.6566 \\
\hline \multicolumn{4}{|l|}{ Religion } \\
\hline Islam & 1 & - & - \\
\hline Christianity & 0.5507 & $0.1953-1.5531$ & 0.2594 \\
\hline \multicolumn{4}{|l|}{$\begin{array}{l}\text { Know duration of HIV } \\
\text { infection (years) }\end{array}$} \\
\hline $1-10$ & 1 & - & - \\
\hline$\geq 10$ & 0.5546 & 0.18501 .6621 & 0.2925 \\
\hline \multicolumn{4}{|l|}{$\bar{E}$ ducational status } \\
\hline No formal education/primary & 1 & - & - \\
\hline Secondary/tertiary & 5.8199 & $2.0393-16.6095$ & $0.0010^{\mathrm{b}}$ \\
\hline \multicolumn{4}{|l|}{ Residence } \\
\hline Rural & 1 & - & - \\
\hline Urban & 2.1171 & 0.69966 .4067 & 0.1843 \\
\hline \multicolumn{4}{|l|}{ Children alive } \\
\hline $1-2$ & 1 & - & - \\
\hline$\geq 3$ & 1.5460 & 0.50714 .7131 & 0.4437 \\
\hline \multicolumn{4}{|l|}{ Parity } \\
\hline $1-3$ & 1 & - & - \\
\hline$\geq 4$ & 0.8525 & $0.2724-2.6681$ & 0.7840 \\
\hline \multicolumn{4}{|l|}{$\bar{D}$ isclosed status to partner } \\
\hline No & 1 & - & - \\
\hline Yes & 4.3307 & $1.2072-15.5358$ & $0.0245^{\mathrm{b}}$ \\
\hline \multicolumn{4}{|l|}{ Partner's HIV status } \\
\hline Unknown & 1 & - & - \\
\hline Negative & 1.9070 & $0.5737-6.3386$ & 0.2922 \\
\hline Positive & 1.1836 & $0.3533-3.9649$ & 0.7847 \\
\hline \multicolumn{4}{|l|}{ Viral load copies $/ m l$} \\
\hline$>1000$ & 1 & - & - \\
\hline$\leq 1000$ & 1.1722 & $0.4369-3.1454$ & 0.7524 \\
\hline
\end{tabular}

${ }^{\mathrm{b}}$ statistically significant.

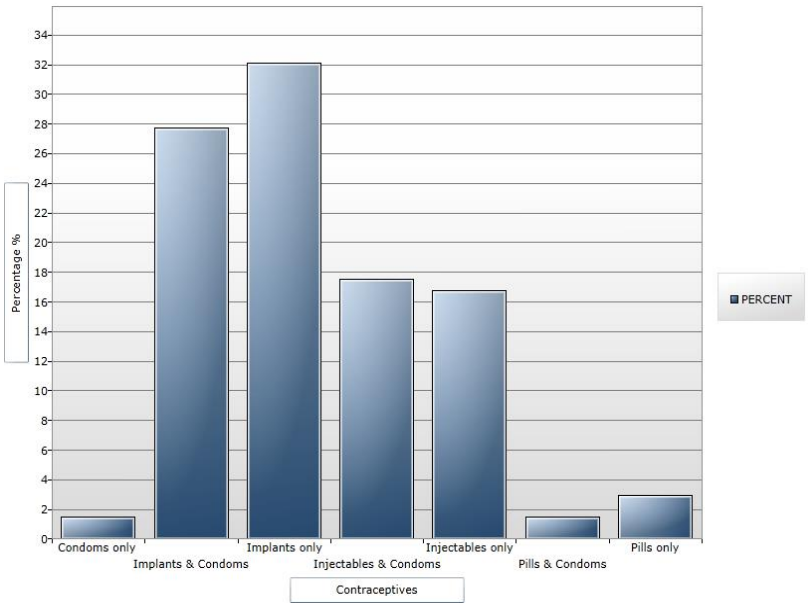

Fig. 1. Distribution of contraception choice of participants.

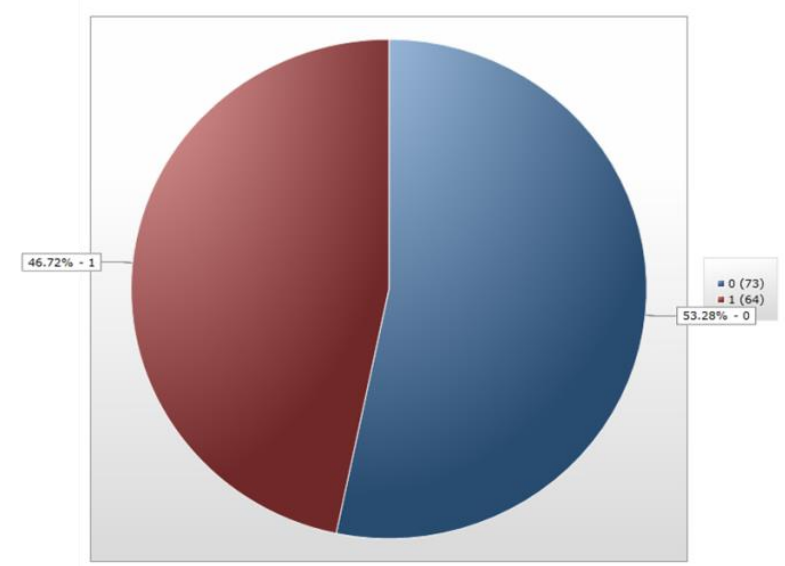

Fig. 2. Distribution of clients' utilization of single or dual contraception.

\section{DISCUSSION}

In this study, 137 (143 before excluding missing data) HIV-infected women accessed the FP unit integrated with the ART facility services during the 1 year study period. Out of the total number of women of childbearing age enrolled for care in the facility during the same period (4291), the prevalence of clients seeking contraception within the FP unit of the facility was low (3.3\%), and this may have been exaggerated by poor record keeping. Reasons that may be proffered for this low number aside from poor documentation include: preference to seek contraception elsewhere, use of methods that did not require visiting a facility, desire for methods that were not available in the facility or required referral elsewhere (e.g. IUCD, permanent surgical methods), use of natural methods, total abstinence, desire to have children or already pregnant, lack of empowerment to use contraception, lack of interest/disclosure, unknown partner status, fear of side effects, postpartum state, ignorance and other sociocultural factors. Some of these reasons have been reported in previous studies [16], [21], [29]-[31].

All the clients received FP counselling, and were predominantly urban dwellers in the age group $30-39$ years, married, multiparous, of Christian faith and had secondary/tertiary education which are some factors known 
to influence uptake of contraceptive [16], [20], [21], [29], [30], [32]. The most frequent choice of contraception was the implant, used in $61.3 \%$ of clients, followed by condoms $48.2 \%$, injectables $32.9 \%$ and pills $4.4 \%$. Fifty-three percent used these methods exclusively while $46.7 \%$ used dual methods, and the commonest combination was condoms and implants (27.7\%). This is quite different from the pattern in a previous study in Jos where condom use $(67.8 \%)$ was the commonest method [33]. The frequency of dual method $(46.7 \%)$ use was similar to that reported in the previous Jos study $(50 \%)$, though in their study the commonest combination was condom and injectables $(41.8 \%)$. The pattern was also different from that in other parts of Nigeria where male condoms were the most frequent method used, followed by pills. These studies also documented abstinence and use of IUCDs which were not used in the current study, but little or no use of injectables [16], [25], [34]. Absence of linkage between FP services and ART facility, as well as differences in sociodemographic factors may have accounted for the differences. Dual method usage in the index study was significantly associated with disclosure of status to partner and secondary/tertiary educational level and was considered low because it was practiced by less than half of the population. This may have been related to noninvolvement of male partners in FP counselling. The DM usage was however higher than levels reported by other researchers in southern Nigeria 6.1\% and 27.2\% [25], [35], and some parts of Africa-Ethiopia (6.4\%), Zambia 25\%, Uganda $17.7 \%$ [11], [31], [36]. Factors associated with lower odds of DM usage were illiteracy, non-marriage relationships(single, divorced, widowed), nondisclosure of HIV status and lack of awareness [11],[35], whereas higher odds of DM usage were associated with one or more living children, CD4 count $>350$ cells $/ \mathrm{ml}$ [31]. In another hospital based study in Uganda, none of the participants used DM, and the overall usage of contraception was low which the researchers implied was due to lack of sensitization of the women on the important role of contraception in the fight against HIV [21]. A common finding in most of the studies was low prevalence of contraception use including DM among HIV-infected women, and some clients indicated preference for accessing FP services from ART facilities which led authors to conclude that the low prevalence was due to absence of linkage between FP and ART facility [32]. It is encouraging to note that respondents in similar studies have also reported that making FP services available within the ART facility would improve access for them [22]. The higher prevalence of DM usage in this study where FP is linked to ART care, in comparison with the lower prevalence found in these other studies without linkages corroborate this. However, the 46.7\% DM usage recorded in this study is still considered low as it represents less than half of the population studied implying that establishing FP and ART linkages alone may not be sufficient to achieve optimal levels of DM uptake so more needs to be done to improve uptake. This same conclusion was also drawn by Hancook et al in Zambia who recommended that to augment the promising strategy of linking FP and ART services, there should be additional focus on sexual activity and advocacy for dual method use [22]. The results of this current study also reflect a need for involvement of male partners in FP counselling, while sensitization strategies to encourage both disclosure of HIV status to partners and partner testing need to be promoted.

It was observed that IUCDs were not offered to clients in this study thus reducing the range of effective contraceptive options available to the clients and probably contributing to a greater unmet need for contraception. In contrast other studies have recorded IUCD use in HIV-infected women with one study in Ethiopia reporting this method as the most frequently used [11]. The risk of sexually transmitted infections and pelvic inflammatory disease are valid concerns to negate the use of IUCDs in this group of women, however the safety of IUCDs for use in HIVinfected women has been established and it may be offered to women who meet a selection criteria which include: nonengagement in high risk sex, monogamous relationships, virologically suppressed, negative to screening for STIs, absence of previous history of PID or ectopic pregnancy, good health seeking behavior and continuing access to medical services [30], [37], [38]. The absence of IUCD in this study was considered a gap in provision of contraceptive options. HIV-positive women should be enlightened about and where possible, have access to all the options of contraceptive methods they are eligible for. In South Africa, HIV-positive women who had low level of awareness about IUCDs were found to be interested in using IUCDs when provided with appropriate information about the method [39].

\section{CONCLUSION}

In conclusion, this study has highlighted the importance of FP and ART linkages however the results portray low client patronage, non-use of IUCD as a contraceptive method and low uptake of DM. All of these can be improved upon by screening of clients to identify unmet needs with the aim to address them, keeping a complete log of all clients who present to the unit but have to be referred or redirected elsewhere, introducing IUCD to widen the range of methods available, intensifying FP counselling to involve partners, encouraging HIV status disclosure to partners, and partner HIV testing as strategies to enhance uptake of DM as well as promote correct and consistent use of condoms. These findings show that the benefits of FP/ART linkages rely not only on the establishment of the linkages but require also that the services provided should be optimal. Raising awareness of the availability and importance of FP services needs to be continuous.

\section{LIMITATIONS}

This was a retrospective study using convenience sampling; therefore it was not representative of the general population. Also, because the data was not specifically designed for the study, some useful information was not available from the records. 


\section{ACKNOWLEDGMENT}

Halima Sule thanks the Family Planning and Data units for assistance with retrieving the required data for this study.

\section{REFERENCES}

[1] WHO. Global Health Observatory data. (2018). Available at: https://www.who.int/gho/hiv/en/ [Accessed on October 12, 2019].

[2] UNAIDS. (2019). The global HIV\& AIDS statistics. Available: https://www.unaids.org/en/resources/fact-sheet.

[3] UNAIDS. (2018). Start free. Stay free. AIDS free:2017 progress report. Available https://www.unaids.org/en/resources/documents/2018/start-free--stayfree-aids-free-2017-progress-report.

[4] Avert.org. (2018). HIV and AIDs in Nigeria. Available: https://www.avert.org/professionals/hiv-around-world/sub-saharanafrica/Nigeria.

[5] NACA. (2017). National Strategic Framework on HIV and AIDS: 2017-2021. Available https://www.childrenandaids.org/sites/default/files/201711/NATIONAL-HIV-AND-AIDS-STRATEGICFRAMEWORK.pdf.

[6] UNAIDS. (2016). prevention gap report. Available: https://www.unaids.org/sites/default/files/media_asset/2016preventio n-gap-report_en.pdf.

[7] B. Zaba, C. Calvert, M. Marston, R. Isingo, J. Nakiyingi-Miiro, T Lutalo, et al. "Effect of HIV infection on pregnancy-related mortality in sub-Saharan Africa:secondary analyses of pooled communitybased data from the network for analysing longitudinal populationbased HIV/AIDS data on Africa (ALPHA)", Lancet. vol 381, no 9879, pp 1763-1771. 2013.

[8] S. Darak, I. Hutter, V. Kulkarni, S. Kulkarni and F. Janssen. "High prevalence of unwanted pregnancies and induced abortions among HIV-infected women from West India: Need to emphasize dual method use?", AIDS Care. vol. 28, no 1, pp 43-51, Aug 2016.

[9] O. V. Adeniyi, A. I. Ajayi, M. G. Moyaki , D. T. Goon, G. Avramovic and J. Lambert. "High rate of unplanned pregnancy in the context of integrated family planning and HIV care services in South Africa", BMC Health Serv Res.vol. 18, no 140, 8pgs, Feb. 2018.

[10] V. Iyun, K. Brittain, T. K. Phillips, S. le Roux, J. A. McIntyre, A. Zerbe et al. "Prevalence and determinants of unplanned pregnancy in HIV-positive and HIV-negative pregnant women in Cape Town, South Africa: a cross-sectional study", BMJ Open. vol. 8, no 4, e019979, Apr. 2018.

[11] A. G. Mersha, D. A. Erku, S. A. Belachew, A. A. Ayele, B. M. Gebresillassie et al. "Contraceptive use among HIV-positive and negative women: implication to end unintended pregnancy." Contracept Reprod Med. vol. 4, no 3, Feb. 2019.

[12] WHO. (2020) HIV/AIDS.Mother to child transmission of HIV. Available: https://www.who.int/hiv/topics/mtct/en.

[13] C. Calvert and C. Ronsmans. "HIV and the risk of direct obstetric complication: asystematic review and meta-analysis." PLoS ONE, vol. 8, no 10, e74848, Oct. 2013.

[14] H. W. Reynolds, B. Janowitz, R. Homan, L. Johnson. "The value of contraception to prevent perinatal HIV transmission." Sex Transm Dis, vol.33, no 6, pp. 350-356, Jun 2006.

[15] WHO. (Dec 2015). "Health in 2015: from MDGs, Millennium Development Goals to SDGs, Sustainable Development Goals." Available: https://www.who.int/gho/publications/mdgs-sdgs/en/ [Accessed on February 22, 2020], Dec 2015.

[16] E. E. Chinaeke, C. Fan-Osuala, M. Bathnna, C. E. Ozigbu, B. Olakunde, H. O. Ramadhani et al. "Correlates of reported modern contraceptive use among postpartum HIV-positive women in rural Nigeria: an analysis from the MoMent prospective cohort study." Reprod Health,vol 16, no 2, Jan. 2019.

[17] C. C. Okigbo, D. R. McCarraher, M. Chen, U. Gwarzo, G. Vance, and O. Chabikuli. "Unmet need for contraception among clients of FP/HIV Integrated services in Nigeria: The role of partner opposition.” Afr J Reprod Health, vol.18, no 2, pp. 134-143, Jun. 2014.

[18] I. Yaya, A. A. Patassi, D. E. Landoh, E. M. Bignandi, K. Kolani, A. D. Namoro AD et al. "Modern contraceptive use among HIV-infected women attending HIV care centres in Togo: a cross-sectional study." BMJ Open, vol.8, no 4, e019006, Apr. 2018.

[19] F. A. Abubeker, M. B. Fanta, and V. K. Dalton. "Unmet need for contraception among HIV-positive women attending HIV care and treatmentservice at Saint Paul's Hospital Millennium Medical
College, Addis Ababa, Ethiopia.” Int J Rep Med, ID3276780, 7pgs, Aug. 2019.

[20] J. D. Damian, J. M. George, E. Martin, B. Temba, and S. E. Msuya "Prevalence and factors influencing modern contraception use among HIV-positive women in Kilmanjaro region, northern Tanzania.' Contracept and Reprod Med, vol.3 no 7, 9 pgs. May 2018.

[21] F. Bongomin, M. Chelangat, A. Eriatu, B. C. Onen, P. Cheputyo, S. A. Godmercy et al. "Prevalence and factors associated with contraception use among $\mathrm{HIV}$-infected women of reproductive age attending infectious disease clinic at Gulu Regional Referral Hospital, Northern Uganda.” Biomed Res Int.2018:9680514, Jun. 2018.

[22] N. L. Hancock, C.J. Chibwesha, S. Bosomprah, J. Newman, M Mubiana-Mbewe, E. S. Sitali et al. "Contraceptive use among HIVinfected women and men receiving antiretroviral therapy in Lusaka, Zambia: a cross-sectional survey.” BMC Pub Healt. Vol.16, no 392, 8pgs, May 2016.

[23] A. A. Creanga, D. Gillespie, S. Karklins and A. O. Tsui. "Low use of contraception among poor women in Africa: an equity issue." Bull World Health Organ, vol. 89 no 4, pp 258-266. Feb. 2011.

[24] R. Wilcher and W. Cates. "Reproductive choices for women with HIV." Bull World Health Organ, vol.87, no 11, pp 833-839, Nov. 2009.

[25] C. E. Enyinda and B. O. Enaohwo. "Contraception prevalence and pattern among HIV positive women in Port Harcourt, south-south Nigeria." J Reproduc Contracep, vol. 23 no 3, pp186 - 192. Sept. 2012.

[26] A. M. Mulongo, R. W. Lihana, J. Githuku, Z. Gura and S. Karanja. "Factors associated with uptake of dual contraception among HIVinfected women in Bungoma County, Kenya: a cross sectional study.' PAMJ, vol. 28 no 1, S 2. Nov. 2017.

[27] F. Abay, H. Y. Yeshita, F. A. Mekonnen and M. Sisay. "Dual contraception method utilization and associated factors among sexually active women on antiretroviral therapy in Gondar City, northwest Ethiopia: a cross sectional study." BMC Women's Health, vol 20 no 26, 9 pgs. Feb. 2020.

[28] B. Joshi, G. Velhal, S. Chauhan, R. Kulkarni, S. Begum and Linkage Study Team. "Linking HIV and family planning services to improve dual methods of contraception among women infected with HIV in Mumbai, Maharashtra, India.” Indian J Med Res, vol 143 no 4, pp 464 - 473. Apr. 2016.

[29] A. U. Shehu, I. A. Joshua and Z. Umar. "Knowledge of contraception and contraceptive choices among Human Immunodefficiency Viruspositive women attending antiretroviral clinics in Zaria, Nigeria." Sub-Sahr Afr J Med, vol. 3, no 2, pp84-90, Jun. 2016.

[30] H. S. Mitchell and E Stephens. "Contraception choice for HIVpositive women.” Sex Transm Infect, vol. 80 no 3, pp 167-173. Jun. 2004.

[31] C. J. Chibwesha, M. S. Li, C. K. Matoba, R.K. Mbewe, B. H. Chi, Stringer JSA, et al. "Modern contraceptive and dual method use among HIV-infected women in Lusaka, Zambia." Infect dis Obs Gynecol, vol 2011, ID261453, 8 pgs, Oct. 2011.

[32] K. A. Alene and K. A. Atelell. "Contraceptive use and method preference among HIV-positive women in Amhara region, Ethiopia.' BMC Women's Health, vol 18, no 97. Jun. 2018.

[33] A. E. Ogbe and J. T. Mutihir. "Pattern of contraception among HIVpositive women in Jos University Teaching Hospital.” Niger J Med, vol. 21, no 1 pp 11-15, Jan. 2012.

[34] J. D. Ojule, E. O. Oranu and B. C. Unamba. "Contraceptive practice among HIV positive women attending antiretroviral clinic at the University of Port Harcourt Teaching Hospital, Port Harcourt, southern Nigeria.” East Afr Med J, vol. 92, no 1, pp 9-14, Jan. 2015.

[35] L. O. Lawani, A. K. Onyebuchi and C. A. Iyoke. "Dual method use for protection of pregnancy and disease prevention among HIVinfected women in southeast Nigeria." BMC Women's Health, vol. 14, no 39, 6 pgs, Mar. 2014.

[36] C. I. Nieves, A. Kaida, G. R. Seage, J. Kabakyenga, W. Muyindike, Y. Boum et al. "The influence of partnership on contraceptive use among HIV-infected women accessing antiretroviral therapy in rural Uganda." Contracept, vol. 92, no 2, pp 152-159. Aug. 2015.

[37] WHO. Medical eligibility criteria for contraceptive use 5th edition. (2015).

Available: https://www.who.int/reproductivehealth/publications/family_planning /MEC-5/en/.

[38] O. Heikinheimo, P. Lehtovirta, I. Aho, M. Ristola and J. Paavonen. "The levonorgestrel-realising intrauterine system in Human Immunodeficiency Virus-infected women: a 5-year follow-up study." Am J Obstet Gynecol, vol 204, no 2 pp 126.e1-4, Feb. 2011.

[39] C. S. Todd, H. E. Jones, T. C. Garber, H. Afnan-Holes, H. Woolgar, L. Bekker et al. "Awareness and interest in intrauterine contraceptive 
www.ejmed.org

device use among HIV-positive women in Cape Town, South Africa."

Infect Dis Obstet Gynecol, vol 2012, ID956145, 8 pgs, Jun. 2012. 